\title{
MUTU FISIK DAN TEKNIK PEMATAHAN DORMANSI BENIH KAYU KUKU (Pericopsis mooniana (Thw.) Thw.)
}

\author{
The Physical Quality and Breaking Dormancy Treatment of Pericopsis mooniana (Thw.) Thw. \\ Seeds
}

\author{
Arum Sekar Wulandari ${ }^{1 *}$ dan Afrida Rizka Farzana ${ }^{1}$
}

(Diterima September 2020/Disetujui Desember 2020)

\begin{abstract}
The presence of Pericopsis mooniana (Thw.) Thw. in nature is endangered. Meanwhile, Pericopsis mooniana plants have its obstacles in generative propagation because the seeds have mechanical dormancy. Studies carried out to: (1) observe the morphology of pods, seeds and sprouts of Pericopsis mooniana; (2) determine the physical quality of Pericopsis mooniana seeds, and (3) analyze the proper dormancy breaking treatment for Pericopsis mooniana seeds. Research is conducted in laboratories and in greenhouses. The physical quality of the seeds measured was the weight of 1,000 seeds and the moisture content. The treatment for breaking the dormancy of the Pericopsis mooniana seeds were control, scarification of the seeds using nail clippers and soaking in hot to cold water for 48 hours. Morphologically, the fruit of Pericopsis mooniana is podshaped, with orange seeds, oval-shaped and curved edges. Pericopsis mooniana sprouts include in the epigeal type. In $1 \mathrm{~kg}$ of weight there are \pm 4,000 Pericopsis mooniana seeds, with the post harvest seed moisture content amounting to $7.62 \%$. The dormancy breaking treatment of Pericopsis mooniana seeds increased seeds germination by $60 \%$ compared to controls. The scarification of Pericopsis mooniana seeds using nail clippers for breaking mechanical dormancy is the best treatment because it can increase the number of seeds germinating in a short time and simultaneously.
\end{abstract}

Key words: breaking seed dormancy, morphology, Pericopsis mooniana, physical quality, seed scarificatio

\section{PENDAHULUAN}

Kayu kuku (Pericopsis mooniana (Thw.) Thw.) merupakan salah satu tumbuhan yang tergolong dalam famili Fabaceae. Jenis ini merupakan kayu lokal Sulawesi karena keberadaannya tumbuh secara alami di Sulawesi Tenggara, Kabupaten Kolaka (Husna 2015). Kayu kuku merupakan tumbuhan yang memiliki kayu yang tergolong kayu mewah, kayunya termasuk dalam kelas awet I-II (Husna 2015). Kayu kuku banyak dimanfaatkan oleh manusia di antaranya untuk konstruksi bangunan, barang kerajinan, mebel, vinir (Pandit 2004), geladak kapal, jembatan, bantalan rel kereta api, kusen, badan kendaraan (Husna 2015).

Saat ini keberadaan pohon kayu kuku di alam terancam punah. Berdasarkan status konservasi pada tahun 2014 dari the International Union for Concervation of Nature (IUCN) dalam kategori Red List, kayu kuku masuk dalam kategori status rawan punah (Anoop et al. 2016). Fakta ini menunjukkan bahwa perlu dilakukannya budidaya kayu kuku agar ketersediaannya di alam tetap terjaga. Budidaya kayu kuku dapat dilakukan dengan perbanyakan secara vegetatif maupun generatif.

Perbanyakan kayu kuku secara generatif memiliki prospek yang baik, hal ini karena pohon kayu kuku

\footnotetext{
${ }^{1}$ Departemen Silvikultur, Fakultas Kehutanan dan Lingkungan, Institut Pertanian Bogor

* Penulis korespondensi:

e-mail: rr_arum@yahoo.com
}

berbuah setiap tahun. Namun, ada kendala terkait morfologi polong dan benih kayu kuku yang dapat mempengaruhi perkecambahan benihnya. Secara alami, polong kayu kuku yang telah masak akan jatuh ke tanah, namun kulit polongnya yang tebal membutuhkan waktu yang lama untuk mengering dan membuka dengan baik (Suhartati et al. 2015). Benih kayu kuku memiliki kulit benih yang keras. Benih yang demikian biasanya memiliki dormansi mekanik. Beberapa metode sudah dilakukan untuk mematahkan dormansi benih kayu kuku, yaitu: (1) perendaman benih dalam air panas pada suhu awal $80{ }^{\circ} \mathrm{C}$ selama 48 jam yang menghasilkan daya kecambah benih sebesar 71,33\% (Sandi et al. 2014). (2) Perendaman benih kayu kuku dalam air panas pada suhu awal $80{ }^{\circ} \mathrm{C}$ selama 24 jam menghasilkan daya kecambah benih sebesar 76\% (Suhartati dan Alfaizin 2017). (3) Perendaman benih dalam air panas dengan suhu awal 100 ${ }^{0} \mathrm{C}$ selama 20 menit menghasilkan daya kecambah benih sebesar 84,7\% (Utami 1994). (4) Skarifikasi dengan pengupasan kulit benih $<0,5 \mathrm{~cm}$ dan benih ditanam denga teknik kultur jaringan, menghasilkan daya kecambah benih sebesar $90 \%$ (Nursyamsi 2016). Berdasarkan hasil penelitian yang pernah dilakukan, perlakuan skarifikasi benih belum diterapkan pada budidaya kayu kuku secara konvensional, untuk itu perlu dilakukan penelitian mengenai hal tersebut. Tujuan dari penelitian ini adalah (1) mengamati morfologi polong, benih dan kecambah kayu kuku; (2) menetapkan mutu fisik benih kayu kuku, dan (3) dan mengkaji teknik pematahan dormansi yang tepat untuk benih kayu kuku. 


\section{METODE PENELITIAN}

\section{Waktu dan Lokasi Penelitian}

Penelitian dilaksanakan pada bulan Januari sampai bulan Mei 2020 di Laboratorium Silvikultur dan Rumah Kaca Departemen Silvikultur Fakultas Kehutanan dan Lingkungan IPB.

\section{Alat dan Bahan}

Alat yang digunakan dalam penelitian ini adalah Galah untuk pengunduhan, penggaris, pisau, timbangan digital, oven, pasir, autoklaf, gunting kuku, dan wadah atau nampan. Bahan yang digunakan yaitu Polong Benih kayu kuku (Pericopsis mooniana (Thw.) Thw.) dan air panas untuk perendaman setelah pengikiran.

\section{Pengunduhan Polong Kayu Kuku}

Polong kayu kuku diunduh di sekitar Fakultas Kehutanan dan Lingkungan, Institut Pertanian Bogor (koordinat: $\left.\quad 6^{\circ} 33^{\prime} 24.59^{\prime \prime} \mathrm{S} \quad 106^{\circ} 43^{\prime} 45,11^{\prime} \mathrm{E}\right)$. Pengunduhan polong dilakukan dengan cara memanjat pohon secara langsung dan menggunakan galah.

\section{Ekstraksi dan Seleksi Benih Kayu Kuku}

Morfologi polong kayu kuku dideskripsikan, kemudian diukur panjang dan lebarnya. Ekstraksi benih dilakukan dengan cara membuka kulit polong untuk mengeluarkan benih yang ada di dalamnya. Jumlah benih pada masing-masing polong kemudian dihitung. Morfologi benih kayu kuku dideskripsikan, kemudian diukur panjang dan lebarnya. Seleksi benih dilakukan dengan cara memilih benih yang berwarna oranye, bebas hama dan penyakit, tidak rusak, dan sudah masak baik secara fisik maupun fisiologis.

\section{Pengujian Mutu Fisik Benih Kayu Kuku}

Pengujian mutu fisik benih terdiri atas penentuan berat 1.000 butir benih dan penetapan kadar air benih.

\section{Penentuan berat 1.000 butir benih}

Penentuan ini digunakan untuk menghitung jumlah benih dalam $1 \mathrm{~kg}$ berat. Menurut Dephut (2009) perhitungan berat 1.000 butir benih dilakukan dengan rumus sebagai berikut:

Keterangan:

$$
\mathrm{s}^{2}=\frac{\mathrm{n}\left(\sum \mathrm{x}^{2}\right)-\left(\sum x\right)^{2}}{\mathrm{n}(\mathrm{n}-1)}
$$

$\mathrm{x}=$ berat tiap ulangan dalam $\mathrm{g}$ (100 benih)

$\mathrm{n}=$ jumlah ulangan (8)

$\sum=$ jumlah

$\mathrm{s}^{2}=$ ragam

Keterangan:

$$
\mathrm{s}=\sqrt{ } \mathrm{s}^{2}
$$

$\mathrm{s}=$ standar deviasi

Keterangan:

$$
\mathrm{CV}=\frac{\mathrm{s}}{\mathrm{x}} \times 100 \%
$$

$\mathrm{x}$ = rata-rata berat 100 benih

$$
\text { Jumlah benih per } \mathrm{kg}=\frac{1000}{\text { Berat } 1000 \text { benih }} \times 1000
$$

\section{Kadar air benih}

Penetapan kadar air dilakukan sesuai standar ISTA (2013) dengan menggunakan metode oven suhu $103{ }^{\circ} \mathrm{C}$ selama $17 \mathrm{jam}$. Kadar air dapat dihitung dengan menggunakan rumus sebagai berikut:

$$
\text { Kadar Air ( } \%)=\frac{\text { susut berat }}{\text { berat awal }} \times 100 \%=\frac{\mathrm{M} 2-\mathrm{M} 3}{\mathrm{M} 2-\mathrm{M} 1} \times 100 \%
$$

Keterangan:

M1 = berat dalam gram dari wadah dan tutupnya

M2 = berat dalam gram dari wadah, tutup, dan isinya sebelum pengeringan

M3 = berat dalam gram dari wadah, tutup, dan isinya sesudah pengeringan

\section{Pengujian Perkecambahan Benih Kayu Kuku}

\section{Persiapan media tabur}

Media tabur yang digunakan adalah media pasir halus yang lolos saringan $0.8 \mathrm{~mm}$ dan tertahan pada saringan $0.05 \mathrm{~mm}$. Media yang telah disaring disterilkan dengan menggunakan autoklaf pada suhu $121{ }^{\circ} \mathrm{C}$, tekanan 1 atm selama 1 jam.

\section{Pematahan dormansi benih}

Perlakuan pematahan dormansi benih kayu kuku yang dilakukan adalah: (1) kontrol (tanpa pematahan dormansi), (2) pengikiran benih kayu kuku dengan menggunakan gunting kuku pada salah satu sisi benih, dan (3) perendaman benih kayu kuku dalam air panas pada suhu awal $80-90{ }^{\circ} \mathrm{C}$ selama 10 menit dilanjutkan dengan perendaman dengan air suhu ruang selama 48 jam.

\section{Penanaman benih}

Benih kayu kuku yang telah diberi perlakuan ditanam pada wadah perkecambahan yang telah berisi media pasir halus steril. Satu wadah berisi 50 benih kayu kuku. Proses perkecambahan benih sampai munculnya kecambah yang utuh diamati dan disdeskripsikan.

\section{Pemeliharaan dan Pengamatan}

Pemeliharaan dilakukan adalah penyiraman yang dilakukan setiap hari pada pagi atau sore hari. Pengamatan perkecambahan dilakukan setiap hari selama 60 hari. Peubah yang diamati antara lain: persentase perkecambahan benih, potensi tumbuh maksimum, rata-rata hari berkecambah, dan nilai perkecambahan.

\section{Rancangan percobaan dan analisis data}

Rancangan percobaan yang digunakan adalah rancangan acak lengkap (RAL) dengan pola faktorial yang terdiri dari satu faktor, yaitu pematahan dormansi. Faktor pematahan dormansi terdiri atas 3 taraf, yaitu kontrol, pengikiran dengan gunting kuku, dan perendaman air panas 10 menit dilanjutkan air biasa 48 jam. Masing-masing taraf terdiri atas 3 ulangan dengan 1 ulangan terdiri atas 50 benih. Total benih yang digunakan sebanyak 450 benih.

Data yang diperoleh dari pengamatan kuantitatif diuji dengan analisis ragam (uji F). Hasil yang berpengaruh nyata pada uji $\mathrm{F}$ diuji lanjut dengan menggunakan Duncan Multiple Range Test (DMRT) pada taraf kesalahan 5\%. Pengolahan data dilakukan dengan menggunakan software IBM SPSS Statistics version 25 . 


\section{HASIL DAN PEMBAHASAN}

\section{Morfologi Polong, Benih dan Kecambah Kayu Kuku}

Buah kayu kuku berbentuk polong (Gambar 1a) yang memiliki beberapa ruang untuk setiap benih di dalamnya (Gambar 1b). Dalam satu polong kayu kuku terdapat 1-6 butir benih. Polong kayu kuku memiliki ukuran panjang 4-16 cm dan lebar $2.5-5.0 \mathrm{~cm}$, berbentuk bulat pada bagian pangkal dan meruncing pada bagian ujungnya. Polong yang belum masak memiliki warna hijau, sedangkan polong yang telah masak akan berwarna kecoklatan seiring dengan pengerasan pada kulit buah karena adanya jaringan gabus yang menebal. Polong kayu kuku termasuk dalam tipe buah indehiscent.

Ekstraksi benih dari polongnya dapat dilakukan secara alami dengan pengeringan karena polong akan merekah dengan sendirinya, tetapi hal tersebut membutuhkan waktu yang lama. Ekstraksi (tanpa proses pengeringan polong) dapat dilakukan secara manual, namun relatif sulit karena kulit polong yang tebal dan keras.

Polong yang telah masak menghasilkan benih yang berwarna oranye, berbentuk lonjong dengan pinggirannya berlekuk (Gambar 2a). Benih kayu kuku termasuk dalam tipe biji dikotil (berkeping dua), memiliki panjang $1.0-1.3 \mathrm{~cm}$ dan lebar $0.7-0.8 \mathrm{~cm}$, dengan kulit benih yang keras. Benih yang dihasilkan dari satu pohon tidak semuanya dalam keadaan baik, dengan ciri: (1) benih sudah terlalu matang dengan warna oranye kemerahan; (2) benih kurus keriput, dan rusak; dan (3) benih terserang fungi pada bagian permukaannya; sehingga diperlukan seleksi benih untuk memilih benih yang baik kualitasnya.

Perkecambahan kayu kuku termasuk dalam tipe epigeal, yaitu kotiledon akan terangkat ke permukaan media tanam saat benih berkecambah (Gambar 2b). Benih kayu kuku yang berkecambah ditandai dengan munculnya radikula (calon akar) dan diikuti dengan

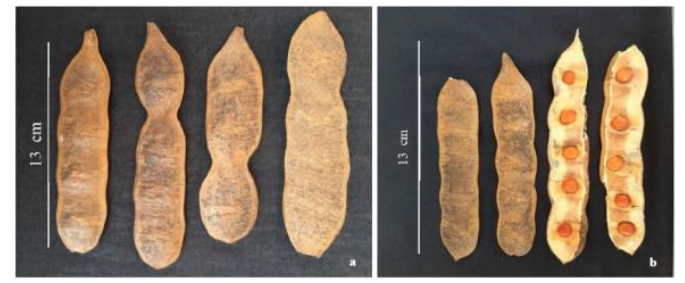

Gambar 1 Morfologi polong kayu kuku yang sudah masak: a. polong utuh, b. polong yang dibuka

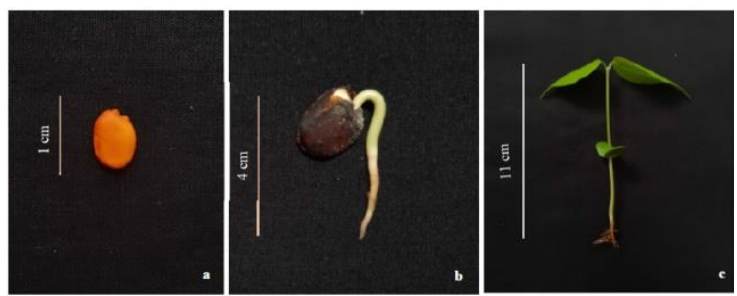

Gambar 2 Perkecambahan benih kayu kuku: a. benih utuh, b. awal benih berkecambah, c. kecambah lengkap pertumbuhan hipokotil yang berwarna putih kekuningan. Hipokotil akan terus tumbuh hingga muncul di atas permukaan media tanam. Ketika hipokotil terus memanjang, kotiledon akan muncul di atas permukaan media tanam namun belum terbuka dan masih terbungkus kulit benih. Kotiledon sedikit demi sedikit akan membuka dan melepaskan kulit benih saat hipokotil mulai tumbuh tegak. Saat kotiledon membuka sempurna dan menghadap ke atas, plumula (calon daun) akan mulai tumbuh. Tumbuhnya akar primer dibarengi dengan tumbuhnya daun pertama. Kecambah kayu kuku yang telah lengkap akan terus berkembang dan menumbuhkan daun-daun baru hingga kotiledon (cadangan makanan) semakin mengerut dan luruh. Kotiledon kecambah kayu kuku akan luruh saat kecambah telah mencapai 4-5 daun, pada umur \pm 90 hari setelah berkecambah (Gambar 2c).

\section{Mutu Fisik Benih Kayu Kuku}

Rata-rata berat 100 butir benih kayu kuku dari 8 ulangan adalah 25,46 g dengan nilai CV (koefisien keragaman) benih kayu kuku sebesar 3,42. Berat 1.000 butir benih kayu kuku adalah 254,6 g, sehingga dalam 1 (satu) $\mathrm{kg}$ berat benih kayu kuku terdapat \pm 4.000 butir benih.

Benih kayu kuku yang digunakan untuk pengukuran kadar air adalah benih yang telah masak secara fisiologis. Hasil pengukuran (Tabel 1) menunjukkan kadar air benih kayu kuku adalah sebesar $7.62 \%$.

\section{Pematahan Dormansi Benih Kayu Kuku}

Benih kayu kuku memiliki dormansi mekanik karena bagian eksokarp benih tebal dan keras. Hasil analisis ragam menunjukkan bahwa perlakuan pematahan dormansi berpengaruh sangat nyata terhadap persentase perkecambahan, potensi tumbuh maksimum, nilai kecambah, dan rata-rata hari berkecambah (Tabel 2). Perlakuan pematahan dormansi dapat meningkatkan perkecambahan benih kayu kuku (Tabel 3). Pematahan dormansi benih kayu kuku dengan cara skarifikasi benih dan perendaman air panas sampai menjadi dingin selama 48 jam dapat meningkatkan perkecambahan benih kayu kuku sebesar $60 \%$. Perlakuan pematahan dormansi juga dapat meningkatkan potensi tumbuh maksimum benih kayu kuku. Potensi tumbuh maksimum menggambarkan viabilitas benih. Nilai potensi tumbuh maksimum dari benih kayu kuku yang dipatahkan dormansinya dengan cara skarifikasi lebih tinggi dibandingkan dengan benih kayu kuku yang dipatahkan dormansinya dengan cara

Tabel 1 Rekapitulasi data penetapan kadar air benih kayu kuku

\begin{tabular}{cc}
\hline Ulangan $^{\mathrm{a}}$ & $\begin{array}{c}\text { Kadar air benih } \\
(\%)\end{array}$ \\
\hline 1 & 7.43 \\
2 & 7.80 \\
3 & 7.62 \\
Rata-rata & 7.62 \\
\hline
\end{tabular}

Dalam 1 ulangan digunakan $5 \mathrm{~g}$ benih 
direndam dalam air panas sampai menjadi dingin selama 48 jam.

Perlakuan pematahanan dormansi tidak selalu dapat meningkatkan perkecambahan benih. Hal ini terjadi pada peubah nilai kecambah. Nilai perkecambahan yang tinggi menunjukkan perkecambahan yang sempurna dan cepat. Perlakuan pematahan dormansi dengan cara skarifikasi benih dapat meningkatkan nilai kecambah benih kayu kuku. Sementara perlakuan pematahan dormansi dengan cara perendaman benih dalam air panas sampai menjadi dingin selama 48 jam tidak dapat meningkatkan nilai kecambah benih kayu kuku (Tabel 3).

Pematahan dormansi benih kayu kuku dapat mempercepat laju perkecambahan benih (Tabel 3). Ratarata hari berkecambah benih kayu kuku yang diberi perlakuan skarifikasi adalah \pm 7 hari, lebih cepat 50 hari dibandingkan dengan perlakuan tanpa pematahan dormansi (kontrol). Sementara, perlakuan perendaman air panas sampai menjadi dingin selama 48 jam membutuhkan rata-rata hari berkecambah lebih lambat 21 hari dibandingkan dengan perlakuan kontrol.

Perlakuan pematahan dormansi benih kayu kuku dapat mempercepat awal mulainya perkecambahan benih (Gambar 3). Benih kayu kuku yang diberi perlakuan pematahan dormansi dengan skarifikasi mulai berkecambah pada hari ke- 5 setelah tanam, berbeda jauh dengan perlakuan tanpa pematahan dormansi (kontrol) yang benihnya baru berkecambah pada hari ke-55 setelah tanam. Puncak perkecambahan pada benih kayu kuku yang diberi perlakuan pematahan dormansi dengan skarifikasi terjadi pada hari ke-7 sampai dengan hari ke11 setelah tanam. Perlakuan pematahan dormansi yang diberi perendaman dengan air panas mulai terjadi pada hari ke-11 setelah tanam dan mencapai puncaknya pada hari ke-50 setelah tanam.

\section{Pembahasan}

Buah kayu kuku berbentuk polong, sehingga termasuk dalam jenis legum, memiliki permukaan kasar dan bergelombang dengan tepian yang keras. Polong kayu kuku termasuk dalam tipe buah indehiscent (Allen dan Allen 1981), yaitu buah tidak terbuka saat telah masak sehingga buah dan benih masih bersatu menjadi unit penyebaran (Sudrajat et al. 2017). Polong kayu kuku yang digunakan penelitian ini memiliki ukuran panjang 4-16 cm dan lebar 2.5-5.0 cm, dengan jumlah benih 1-6 butir dalam 1 polong. Ukuran polong kayu kuku yang lebih kecil dari hasil penelitian ini ditemukan dalam penelitian Whitten et al. (2002) dan Suhartati et al. (2015). Polong kayu kuku yang tumbuh di Sulawesi memiliki ukuran panjang $10 \mathrm{~cm}$, lebar $4 \mathrm{~cm}$, dan dalam satu polong berisi 2-4 butir benih (Whitten et al. 2002).

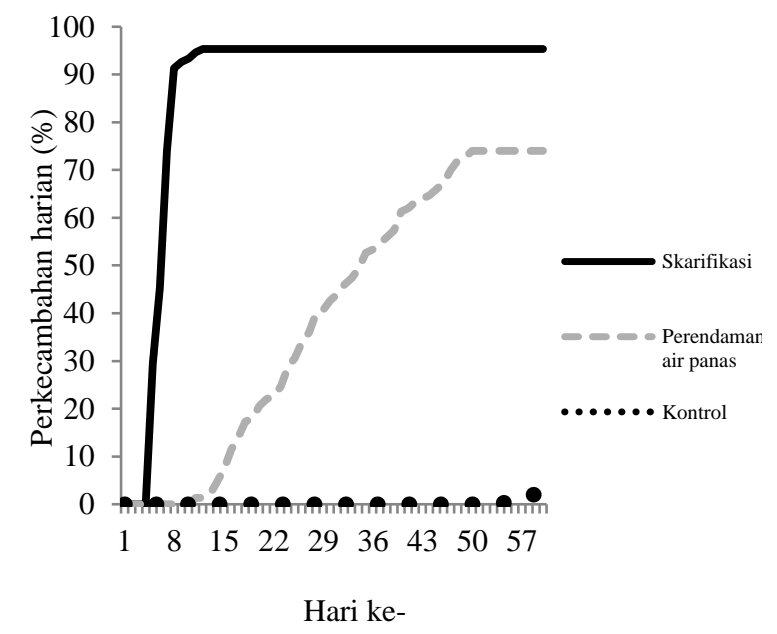

Gambar 3 Persentase perkecambahan harian benih kayu kuku

Hasil yang hampir sama ditemukan pada polong kayu kuku yang tumbuh di kawasan Cagar Alam (CA) Lamedai memiliki 1-4 ruang benih, namun yang terisi hanya 1-3 ruang biji dengan satu biji di setiap ruangnya (Suhartati et al. 2015). Semakin banyak jumlah benih dalam 1 polong maka akan semakin besar ukuran polongnya.

Benih kayu kuku termasuk dalam Angiospermae (biji tertutup), dan dikategorikan tipe biji dikotil (biji

Tabel 2 Rekapitulasi hasil analisis ragam pengaruh pematahan dormansi terhadap perkecambahan benih

\begin{tabular}{ll}
\hline \multicolumn{1}{c}{ Peubah } & P-value \\
\hline Persentase perkecambahan & $<0.0001^{* *}$ \\
Potensi tumbuh maksimum & $<0.0001^{* *}$ \\
Nilai kecambah & $<0.0001^{* *}$ \\
Rata-rata hari berkecambah & $<0.0001^{* *}$ \\
\hline * berpengaruh sangat nyata $(\mathrm{p} \leq 0.01)$ &
\end{tabular}

Tabel 3 Pengaruh pematahan dormansi terhadap peubah perkecambahan benih kayu kuku

\begin{tabular}{lcccc}
\hline \multicolumn{1}{c}{ Perlakuan } & Perkecambah benih $(\%)$ & PTM $(\%)$ & NK & RHB \\
\hline Kontrol & $2.00^{\mathrm{a}}$ & $2.00^{\mathrm{a}}$ & $0.00^{\mathrm{a}}$ & $57.33^{\mathrm{c}}$ \\
Skarifikasi & $60.00^{\mathrm{b}}$ & $95.33^{\mathrm{c}}$ & $3.27^{\mathrm{b}}$ & $6.54^{\mathrm{a}}$ \\
Perendaman air & $61.33^{\mathrm{b}}$ & $74.00^{\mathrm{b}}$ & $0.24^{\mathrm{a}}$ & $29.13^{\mathrm{b}}$ \\
panas & & &
\end{tabular}

Angka yang diikuti huruf yang sama pada baris yang sama menunjukkan tidak berbeda nyata pada uji Duncan $p$ value $<\alpha(0.05), \mathrm{PTM}=$ potensi tumbuh maksimum, $\mathrm{NK}=$ nilai kecambah, $\mathrm{RHB}=$ rata-rata hari berkecambah 
berkeping dua). Benih kayu kuku memiliki bentuk lonjong yang pinggirannya berlekuk dengan ukuran yang relatif seragam. Berdasarkan hasil penelitian, benih kayu kuku memiliki ukuran panjang $1.0-1.3 \mathrm{~cm}$ dan lebar 0.7 - $0.8 \mathrm{~cm}$. Ukuran benih kayu kuku yang hampir sama ditemukan pada penelitian Falanruw (2015) yaitu berukuran panjang $0.9-1.3 \mathrm{~cm}$, sedangkan ukuran benih kayu kuku yang lebih besar ditemukan pada penelitian Suhartati et al. (2015). Kayu kuku yang tumbuh di kawasan CA Lamedai mempunyai ukuran benih $\pm 0.7 \mathrm{x}$ 1.6 x $0.5 \mathrm{~cm}$. Menurut Minor dan Kobe (2019) produksi buah cenderung tidak merata di antara pohon-pohon dari jenis yang sama, yang mungkin disebabkan oleh faktor lingkungan. Produksi buah, termasuk ukuran benih, pada tingkat individu pohon dipengaruhi oleh ukuran pohon, ketersediaan unsur hara di dalam tanah, dan kepadatan dari pohon di sekitarnya.

Benih kayu kuku yang dihasilkan dari pohon yang sama tidak semuanya berkualitas baik. Beberapa benih di antaranya rusak, kurus keriput, dan terserang fungi. Menurut Suryawan et al. (2019), pertumbuhan dan perkembangan polong dalam satu pohon tidak terjadi secara bersamaan. Saat polong belum masak secara fisiologis, benih belum terbentuk dan terisi secara sempurna sehingga akan menghasilkan benih yang keriput dan kurus. Saat polong telah melewati pasca masak fisiologis dan terlambat panen maka benih akan mengalami kemunduran mutu akibat terjadi deraan cuaca di lapangan terhadap benih, sehingga saat panen benih telah mengalami kerusakan. Selain benih rusak/keriput, adanya fungi pada benih menjadi penyebab menurunnya kualitas benih. Menurut Manzanilla et al. (2013), mikroorganisme yang menginfeksi tanaman selama pertumbuhan akan menyebabkan kualitas benih yang dihasilkan rendah. Mikroorganisme tersebut dapat tinggal di dalam benih untuk waktu yang lama, sehingga dapat menyebabkan penurunan kualitas benih, yang akan berdampak pada penurunan kualitas bibit yang dihasilkan.

Mutu fisik benih didasarkan pada data fisik benih yaitu: berat 1.000 butir, kadar air, dan kemurnian (Sudrajat et al. 2017). Berat 1.000 butir benih kayu kuku yang didapatkan dalam penelitian ini adalah 254,6 g dengan nilai CV sebesar 3,42. Nilai CV ini sudah sesuai dengan standar yang ditetapkan oleh Dephut (2009), yaitu nilai $\mathrm{CV}<4,0$. Hasil ini sesuai dengan penelitian Sudrajat et al. (2017) yang menetapkan kisaran mutu fisik benih kayu kuku berdasarkan berat 1.000 butir benih adalah 250- $300 \mathrm{~g}$. Berdasarkan perhitungan diperoleh bahwa dalam $1 \mathrm{~kg}$ berat benih kayu kuku terdapat \pm 4.000 butir. Hasil penetapan berat 1.000 butir benih sangat diperlukan dalam memperkirakan banyaknya (berapa kg) benih kayu kuku yang dibutuhkan untuk kebutuhan bibit saat kegiatan penanaman di lapangan (Suita 2014).

Kadar air merupakan salah satu faktor yang harus diperhatikan pada kegiatan pemanenan, pengolahan, penyimpanan, dan pemasaran benih. Kadar air benih kayu kuku yang dihasilkan dalam penelitian ini adalah 7.62\%. Hasil ini sesuai dengan penelitian Sudrajat et al. (2017) yang menetapkan kisaran mutu fisik benih tanaman hutan berdasarkan kadar air benih untuk kayu kuku adalah $\leq 9 \%$. Kadar benih adalah salah satu faktor terpenting yang mempengaruhi viabilitas dan penyimpanan benih. Oleh karena itu, sangatlah penting merancang metode yang tepat untuk menetapkan standar benih tropis berukuran besar (Krishnapillay et al. 1991).

Benih kayu kuku termasuk dalam benih ortodoks, hal ini didukung oleh hasil penelitian yang menunjukkan kadar air benih pascapengunduhan sebesar 7,62\%. Hasil tersebut sesuai dengan pernyataan Alfaizin et al. (2016) dalam penelitiannya yang menyebutkan bahwa tipe benih kayu kuku adalah benih ortodoks. Benih ortodoks termasuk dalam pengeringan toleran (Benech-Arnold dan Sanchez 2010), yaitu benih yang jika diturunkan kadar airnya hingga $<10 \%$, maka benih masih dapat mempertahankan viabilitasnya. Benih ortodoks dapat disimpan dalam jangka waktu yang lama tanpa kehilangan viabilitasnya, walaupun dalam kondisi suhu dan kelembaban yang rendah (Murrinie et al. 2017).

Benih kayu kuku juga memiliki dormansi, hal ini karena benih membutuhkan waktu yang lama untuk berkecambahan apabila tidak diberi perlakuan pematahan dormansi. Dormansi merupakan sifat alami benih untuk dapat bertahan hidup, namun adanya dormansi dapat menghambat produksi bibit jika teknik pematahan dormansinya yang tepat belum diketahui (Sandi et al. 2014). Dormansi pada benih kayu kuku diduga terjadi karena kulit benih yang tebal dan keras. Perlakuan pematahan dormansi dilakukan agar dormansi benih dapat dihilangkan dan daya kecambah benih dapat meningkat. Perkecambahan merupakan awal pertumbuhan suatu tanaman hingga menjadi tanaman yang siap ditanam di lapangan. Kayu kuku memiliki tipe perkecambahan epigeal karena kotiledon terangkat ke permukaan media saat perkecambahan berlangsung. Menurut Nugroho dan Salamah (2015), tipe epigeal (epigous) ditandai dengan mengembangnya hipokotil dan mendorong kotiledon ke permukaan tanah bersamaan dengan kulit benih dan sisa endosperma.

Hasil penelitian menunjukkan bahwa perlakuan pematahan dormansi pada benih dapat meningkatkan perkecambahan benih kayu kuku. Pematahan dormansi dengan perlakuan skarifikasi dan perendaman air panas sampai dingin selama 48 jam dapat meningkatkan perkecambahan benih hingga 60\% (Tabel 3). Persentase perkecambahan yang lebih tinggi ditemukan dalam penelitian Suhartati dan Alfaizin (2017), yang menyebutkan bahwa pematahan dormansi benih kayu kuku menggunakan perlakuan perendaman dengan air panas pada suhu $80{ }^{\circ} \mathrm{C}$ selama 24 jam dapat meningkatkan perkecambahan sebesar $76 \%$. Persentase perkecambahan benih kayu kuku yang lebih rendah (28\%) ditemukan pada penelitian Sandi et al. (2014). Tingkat dormansi benih dipengaruhi faktor lingkungan (kekeringan, salinitas, fluktuasi suhu, fotoperiode, kesuburan tanah, $\mathrm{pH}$ tanah, kondisi yang mempengaruhi penuaan benih, dan panas radiasi) pada saat pembentukan dan perkembangan benih. Tingkat dormansi yang terbentuk pada benih akan mempengaruhi mudah/sulitnya mematahkan dormansi benihnya, yang pada akhirnya akan mempengaruhi daya kecambah benihnya (Humphries et al. 2018).

Pematahan dormansi dengan cara skarifikasi kayu kuku memberikan nilai potensi tumbuh maksimum tertinggi $(95.33 \%)$ dan waktu perkecambahan tercepat ( \pm 7 hari). Hal ini menunjukkan bahwa perlakuan 
skarifikasi dapat meningkatkan perkecambahan dalam waktu singkat. Hasil yang sama ditemukan dalam penelitian Nurmiaty et al. (2014), pada benih saga manis (Abrus precatorius). Pematahan dormansi benih saga manis dengan skarifikasi menggunakan gunting kuku menghasilkan daya kecambah hingga $100 \%$ dan waktu perkecambahan yang paling cepat dibandingkan dengan perlakuan lainnya.

Rata-rata hari berkecambah dinyatakan dengan ratarata waktu munculnya kecambah (Lubis et al. 2014). Semakin rendah rata-rata hari berkecambah maka semakin cepat benih berkecambah (Lensari 2009). Kecepatan perkecambahan benih berhubungan dengan laju imbibisi oleh kulit benih. Semakin tebal kulit benih, maka semakin lama waktu yang diperlukan oleh air mengisi rongga lapisan kulit benih, sehingga menyebabkan perkecambahan benih lambat (Krisnawati dan Adie 2008). Pengikiran pada benih akan menyebabkan air dan udara lebih mudah masuk ke dalam benih, sehingga proses imbibisi lebih cepat.

Pematahan dormansi dengan cara skarifikasi benih juga dapat meningkatkan nilai perkecambahan benih kayu kuku. Nilai perkecambahan berhubungan dengan laju perkecambahan. Laju perkecambahan menunjukkan rata-rata hari berkecambah, sedangkan nilai perkecambahan menunjukkan persentase benih berkecambah per hari sampai dengan akhir pengamatan (Payung 2009). Laju perkecambahan yang semakin cepat dengan jumlah benih yang semakin banyak akan memperbesar nilai perkecambahan (Wulandari dan Nurhayani 2018). Nilai perkecambahan benih kayu kuku pada perlakuan skarifikasi benih memberikan hasil paling tinggi (Tabel 3). Hal ini menunjukkan bahwa perkecambahan benih kayu kuku yang diberi perlakuan skarifikasi terjadi lebih cepat dan serempak. Menurut Winarni (2009), semakin tinggi nilai perkecambahan maka kesempurnaan dan kecepatan benih berkecambah juga semakin tinggi.

Pematahan dormansi dengan perendaman air panas sampai dingin selama 48 jam juga dapat meningkatkan perkecambahan benih kayu kuku. Namun, waktu perkecambahan benih berlangsung lambat. Hasil penelitian Suhartati dan Alfaizin (2017) menunjukkan bahwa air panas dapat melunakkan lapisan testa yang terdapat pada benih kayu kuku, sehingga memudahkan air dan oksigen masuk ke dalam benih untuk memulai proses perkecambahan. Namun, dalam penelitian ini meskipun benih telah dipatahkan dormansinya dengan menggunakan air panas, dibutuhkan waktu yang lebih lama agar benih dapat berimbibisi dan berkecambah. Hal ini dapat dilihat pada nilai perkecambahan benih yang sama antara benih kayu kuku yang diberi perlakuan pematahan dormansi dengan cara perendaman air panas sampai dingin selama 48 jam dan benih kontrol. Perkecambahan benih yang berlangsung lambat dengan jumlah benih yang berkecambah per hari lebih sedikit dapat menyebabkan nilai puncak perkecambahan rendah.

Fakta dalam penelitian ini menujukkan bahwa: (1) benih kayu kuku tanpa pematahan dormansi (kontrol) dapat berkecambah namun membutuhkan waktu yang sangat lama. (2) Teknik pematahan dormansi dengan cara skarifikasi benih dapat mempercepat waktu berkecambah dan meningkatkan persentase perkecambahan.
Adanya pelukaan pada kulit benih (akibat skarifikasi dengan gunting kuku) menyebabkan air cepat masuk dan radikula dapat cepat muncul. (4) Benih kayu kuku tidak memiliki lapisan lilin pada kulit benihnya. Hal ini bisa dilihat pada saat dilakukannya perendaman pada benih, kulit benih kayu kuku tidak ada yang luruh dan kulit benih tetap keras, sehingga menyebabkan perkecambahan berlangsung lebih lama akibat lambatnya proses imbibisi. Berdasarkan fakta-fakta tersebut, dapat disimpulkan bahwa benih kayu kuku mempunyai dormansi mekanik. Dormansi tersebut dapat dipatahkan dengan cara melakukan skarifikasi pada benih kayu kuku, misalnya dengan menggunakan gunting kuku.

\section{SIMPULAN}

Buah kayu kuku berbentuk polong yang termasuk dalam tipe buah indehiscent. Dalam 1 polong kayu kuku terdapat 1-6 butir benih. Benih kayu kuku berwarna oranye, berbentuk lonjong dengan pinggirannya berlekuk. Apabila benih kayu kuku dikecambahkan, maka kecambah yang tumbuh termasuk dalam tipe epigeal.

Berat 1.000 butir benih adalah 254,6 g sehingga dalam $1 \mathrm{~kg}$ benih terdapat \pm 4.000 butir. Kadar air benih kayu kuku masak fisiologis pascapengunduhan adalah $7.62 \%$. Perlakuan pematahan dormansi benih kayu kuku berpengaruh pada persentase perkecambahan, potensi tumbuh maksimum, nilai kecambah, dan rata-rata hari berkecambah. Pematahan dormansi benih kayu kuku dengan cara skarifikasi benih merupakan teknik yang tepat untuk mematahkan dormansi mekanik yang terdapat dalam benih kayu kuku.

\section{DAFTAR PUSTAKA}

Alfaizin D, Suhartati, Kurniawan E. 2016. Benih dan perkecambahan kayu kuku (Pericopsis mooniana THW). Info Teknis EBONI 13:1-11.

Allen ON, Allen EK. 1981. The Leguminosae: a Source Book of Characteristic, Uses, and Nodulation. Wisconsin (US): The University of Wisconsin Press.

Anoop EV, Sindhumathi CR, Jijeesh CM, Jayasree CE. 2016. Radial variation in wood properties of Nedun (Pericopsis mooniana), an introduced species to South India. Journal of Tropical Agriculture 54:27-34.

Benech-Arnold RL, Sanchez RA. 2010. Handbook of Seed Physiology (Applications to Agriculture). Florida (US): CRC Press.

[Dephut] Departemen Kehutanan. 2009. Peraturan Direktur Jenderal Rehabilitasi Lahan dan Perhutanan Sosial Nomor: P.06/V-SET/2009 tentang Petunjuk Teknis Pengujian Mutu FisikFisiologi Benih. Jakarta (ID): Dirjen Rehabilitasi Lahan dan Perhutanan Sosial.

Falanruw MVC. 2015. Trees of Yap: a Field Guide. Hawaii (US): U.S Departement of Agriculture.

Humphries T, Chauhan BS, Florentine SK. 2018. Environmental factors effecting the germination 
and seedling emergence of two populations of an aggressive agricultural weed; Nassella trichotoma. PLoS ONE. 13:1-25. https://doi.org/10.1371/journal.pone.0199491.

Husna. 2015. Potensi fungi mikoriza arbuskula (FMA) lokal dalam konservasi ex-situ jenis terancam punah kayu kuku [Pericopsis mooniana (Thw.) Thw.] [disertasi]. Bogor (ID): Sekolah Pascasarjana, Institut Pertanian Bogor.

[ISTA] International Seed Testing Association. 2013. International Rules for Seed Testing. Switzerland $(\mathrm{CH})$ : ISTA.

Krishnapillay B, Mansor M, Yap SK, Chua LSL, Ang KC, Abu Bakar SA, Salleh Z. 1991. Determination of seed testing standards moisture content of Hopea odorata seeds. Journal of Tropical Forest Science 4:170-178.

Krisnawati A, Adie MM. 2008. Ragam karakter morfologi kulit benih beberapa genotipe plasma nutfah kedelai. Buletin Plasma Nutfah 1:14-18.

Lensari D. 2009. Pengaruh pematahan dormansi terhadap kemampuan perkecambahan benih angsana (Pterocarpus indicus Will) [skripsi]. Bogor (ID): Institut Pertanian Bogor.

Lubis YA, Riniarti M, Bintoro A. 2014. Pengaruh lama waktu perendaman dengan air terhadap daya berkecambah trembesi (Samanea saman). Jurnal Sylva Lestari 2:25-32.

Manzanilla DO, Janiya JD, Johnson DE. 2013. Membangun Sistem Perbenihan Berbasis Masyarakat. Bogor (ID): Pusat Penelitian dan Pengembangan Tanaman Pangan.

Minor DM, Kobe RK. 2019. Fruit production is influenced by tree size and size-asymmetric crowding in a wet tropical forest. Ecology and Evolution 3:1-15. DOI: 10.1002/ece3.4867.

Murrinie ED, Yudono P, Purwantoro A, Sulistyaningsih E. 2017. Identifikasi sifat benih kawista (Feronia limonia (L.) Swingle) untuk tujuan penyimpanan. Di dalam: Putra AE, Kusumadewi S, Permata PA, Santoso B, Kabib M, editor. Seminar Nasional Teknologi dan Informatika (Buku 1); 2017 Juli 25; Kudus, Indonesia. Kudus (ID): Universitas Muria Kudus. hlm 509-516.

Nugroho TA, Salamah Z. 2015. Pengaruh lama perendaman dan konsentrasi asam sulfat $\left(\mathrm{H}_{2} \mathrm{SO}_{4}\right)$ terhadap perkecambahan biji sengon laut (Paraserianthes falcataria) sebagai materi pembelajaran biologi SMA kelas XII untuk mencapai K.D 3.1 kurikulum 2013. JUPEMASIPBIO 2:230-236.

Nurmiaty Y, Ermawati, Purnamasari VW. 2014. Pengaruh cara skarifikasi dalam pematahan dormansi pada viabilitas benih saga manis (Abrus precatorius [L.]). Jurnal Agrotek Tropika 2:73-77.
Nursyamsi. 2016. Teknik skarifikasi benih kayu kuku (Pericopsis mooniana Thw) untuk mematahkan dormansi melalui kultur jaringan. Prosiding Seminar Nasional from Basic Science to Comprehensive Education; 26 Agu 2016; Makassar. Makassar (ID): Jurusan Biologi, Fakultas Sains dan Teknologi, UIN Alauddin Makassar. hlm 5-10.

Pandit IKN. 2004. Karakteristik struktur anatomi kayu (Pericopsis mooniana Thwaiters). Jurnal Ilmu Kayu dan Teknologi Kayu Tropis 3:1-5.

Payung D. 2009. Uji daya kecambah benih tanjung (Mimusops elengi Linn) dengan berbagai teknik dan lama penyimpanan benih. Jurnal Hutan Tropis Borneo 10:194-200.

Sandi ALI, Indriyanto, Duryat. 2014. Ukuran benih dan skarifikasi dengan air panas terhadap perkecambahan benih pohon kuku (Pericopsis mooniana). Jurnal Sylva Lestari 2:83-92.

Sudrajat DJ, Nurhasybi, Bramasto Y. 2017. Standar Pengujian dan Mutu Benih Tanaman Hutan. Bogor (ID): IPB Press.

Suhartati, Nursyamsi, Alfaizin D. 2015. Mengenal morfologi, tipe buah, dan biji pada pohon kayu kuku (Pericopsis mooniana Thw.). Info Teknis EBONI 12:87-96.

Suhartati, Alfaizin D. 2017. Perkecambahan benih Pericopsis mooniana Thw. berdasarkan warna dan teknik skarifikasi. Jurnal Perbenihan Tanaman Hutan 5:115-124.

Suita E. 2014. Pengaruh seleksi benih terhadap viabilitas benih kaliandra (Calliandra calothysus). Jurnal Perbenihan Tanaman Hutan 2:99-108.

Suryawan KLL, Raka IGN, Mayun IA, Wijaya IKA. 2019. Perbedaan umur panen terhadap hasil dan mutu benih tanaman buncis (Phaseolus vulgaris L.). Jurnal Agroekoteknologi Tropika 8:436-446.

Utami DE. 1994. Efek skarifikasi terhadap perkecambahan dan pertumbuhan semai kayu kuku (Pericopsis mooniana) [skripsi]. Bandung (ID): Universitas Padjajaran.

Whitten T, Henderson GS, Mustafa M. 2002. The Ecology of Sulawesi. Volume 4. Hongkong (HK): Periplus Editions.

Winarni TB. 2009. Pengaruh perlakuan pendahuluan dan berat benih terhadap perkecambahan benih kayu afrika (Maesopsis eminii Engl.) [skripsi]. Bogor (ID): Institut Pertanian Bogor.

Wulandari AS, Nurhayani FO. 2018. Morfologi dan mutu fisik benih kenanga (Cananga odorata (Lam.) Hook.f. \& Thomson forma genuina). Jurnal Silvikultur Tropika 10:95-99. 